\title{
BRITÁNICOS EN LA REGIÓN DE ANTOFAGASTA. LOS NEGOCIOS CONCOMITANTES CON LA MINERÍA DEL DESIERTO DE ATACAMA Y SUS REDES SOCIALES (1880-1930)
}

\author{
José Antonio González Pizarro, ${ }^{1}$ Marcelo Lufin Varas ${ }^{2}$ y Claudio Galeno Ibaceta ${ }^{3}$
}

\section{* Introducción}

Resumen

La presencia británica en la región de Antofagasta entre los años 1880-1930 se verificó en varios ámbitos. Sus inversiones fueron influyentes en la construcción de la conectividad ferroviaria, desde la década de 1870 en adelante. Llegaron a dominar otras iniciativas de empresas privadas ferroviarias tanto de Taltal como de Tocopilla. El núcleo fundamental, lo constituyó el ferrocarril de Antofagasta a Bolivia (FCAB). También se manifestó la gravitación británica en las actividades comerciales y financieras que orientaron el control de la producción salitrera hacia los mercados mundiales. Todo esto exigió una presencia demográfica que fue impulsada por los negocios asentados en la región de Antofagasta donde la mayoría de los miembros de la colonia se vinculó en las actividades ligadas al FCAB y a los sectores técnicos y administrativos de sus empresas salitreras. En tal sentido, la importancia de estos negocios generó redes sociales que de modo significativo incidieron en el rumbo de la sociedad regional.

Palabras claves: británicos - ferrocarril - comercio - salitre - Antofagasta.

\begin{abstract}
The presence of British subjects in the Antofagasta region between 1880 and 1930 can be observed in various fields. Their investments contributed to the establishment of railway connectivity, which began the 1870 s. They controlled other private railway ventures in Taltal and Tocopilla. The main nucleus was the Antofagasta-Bolivia Railway Station. British influence was also seen in the commercial and financial activities directing the control of nitrate (saltpeter) production toward world markets. All this demanded a demographic presence fostered by businesses established in the Antofagasta area, where most of the colony members were linked to activities associated with the Antofagasta-Bolivia Railway Co. (FCAB) and the technical and administrative sectors of saltpeter companies. In this sense, the importance of these businesses created social networks, which significantly influenced the course of regional society.
\end{abstract}

Abstract

Key words: British - railroad - commerce - nitrate - Antofagasta.

Recibido: julio 2014. Aceptado: octubre 2014.
Los británicos, y entre ellos, los ingleses como el segmento de mayor presencia, se relacionaron desde sus inicios con las explotaciones salitreras, mediante la empresa Milbourne Clark y Cía., y después con la Compañía de Salitre y Ferrocarril de Antofagasta donde convergieron capitales nacionales y británicos. Las inversiones británicas estaban ya presentes en Tarapacá y, en el caso de Antofagasta, participaron también en el rubro mercantil a través de casas comerciales que cubrieron el abastecimiento hacia los campamentos mineros del hinterland como del principal puerto de exportación de aquellos productos. Se vincularon, además, con otros sectores mineros y con una agresiva política de conectividad ferroviaria, que enfrentó una temprana competencia de las empresas de carretas. Quizás, la principal actividad británica concomitante con las explotaciones mineras y con la expansión de las casas comerciales sucursales de las establecidas en Londres- fue la ferroviaria que enlazó a las primeras oficinas salitreras como también a la producción de Caracoles con la ciudad de Antofagasta. Un último factor conexo con lo anterior fue el recurso humano británico ligado a la minería. En tal sentido habrá que reparar en tres aspectos relevantes, una primera fase que dice relación con la Compañía de Salitre y Ferrocarril de Antofagasta que promovió la contratación de personal europeo como mano de obra especializada. La Compañía se dividió en 1888 en dos empresas, la de salitre en manos chilenas, que prosiguió con esta política, y la del ferrocarril que quedó en manos británicas, que gestionó la concesión a su favor de los

\footnotetext{
1 Facultad de Ciencias Jurídicas, Universidad Católica del Norte. Casilla 1280, Antofagasta, Chile. Email: jagonzal@ucn. cl

2 Facultad de Economía y Administración, Universidad Católica del Norte. Casilla 1280, Antofagasta, Chile. Email mlufin@ucn. cl

3 Escuela de Arquitectura, Universidad Católica del Norte. Casilla 1280, Antofagasta, Chile. Email: cgaleno@ucn. cl
} 
derechos de agua para la actividad minera y residencial de Antofagasta.

No obstante, habrá que apuntar a una segunda fase que refiere a los capitales británicos en distintas empresas salitreras en los cantones del sur, en la zona de Taltal y Aguas Blancas, y en la actividad terciaria vinculada con éstas, con asiento en las mismas oficinas salitreras o bien en las ciudades costeras. Una tercera fase se vinculó con la adquisición de las propiedades salitreras de la Compañía de Salitres de Antofagasta por parte de Pascual Baburizza, en 1926, con lo cual la presencia de británicos de estas oficinas como personal medio prosiguió.

Respecto del capital social altamente especializado, los británicos solieron contratar en Inglaterra los cuerpos profesionales (ingenieros, mecánicos, médicos, etc.), para atender sus inversiones en el hinterland.

Puede indicarse que la presencia británica en la región fue temprana dadas las actividades de casas comerciales asociadas a la industria salitrera en la región de Tarapacá y los asientos mercantiles en Valparaíso, que actuaron con rapidez en el nuevo territorio salitrero que coincidió en pocos años con la fundación de Antofagasta y el descubrimiento del mineral de Caracoles.

Este trabajo se apoya en distintos fondos documentales, nacionales y regionales, tanto de notarías, registro civil y salitrero, como de información censal y forma parte del proyecto FONDECYT 1130785, año 2014.

\section{* La ciudad de Antofagasta como centro de OPERACIONES DE LAS ACTIVIDADES BRITÁNICAS}

Las operaciones británicas en las actividades salitreras, del ferrocarril y de las casas comerciales principales que operaban en el cono sur de América (desde Antony Gibbs $\mathcal{E}$ Sons; Williamson $\&$ Co.; Duncan Fox, hasta Buchanan Jones $\mathcal{E} C$ o.), han concitado una merecida atención por la historiografía inglesa y chilena desde el despliegue inversionista en el desierto de Atacama, como de la controvertida actuación en el curso de la Guerra del Pacífico, hasta el desencadenamiento del debate de la política salitrera y su resolución con la revolución de 1891 (Bermúdez 1963;
Blakemore 1977; Mayo 1979; Monteon 1975; O'Brien 1982; Ramírez 1972; Ravest 1983; Rippy 1954).

Las actividades financieras y comerciales de los británicos tuvieron como centro neurálgico y asiento de sus administraciones en nuestro país, al puerto de Valparaíso (Estrada 2006), aun cuando en la mencionada ciudad también centraron sus operaciones otras casas comerciales de colonias influyentes en Antofagasta, como la alemana (Couyoumdjian 2000). Las influencias industriales, mercantiles y financieras se manifestaron con fuerza en Iquique y también en el otro extremo del país, Punta Arenas (Martinic 2002).

Se ha indicado que es difícil precisar la cuantía de los capitales británicos en el país (Couyoumdjian 1986), pero sí se puede indicar que hubo cierta correlación entre el aumento del número de súbditos británicos en Chile con el incremento de las inversiones y ambos tuvieron un nexo con la actividad salitrera directa (desde los ferrocarriles hasta las empresas que explotaron el nitrato) como indirecta (desde las casas comerciales, de importaciones y exportaciones hacia la industria salitrera, etc.).

Desde 1895, cuando había 6966 británicos (6838 ingleses), hasta 1907 cuando alcanzó su mayor volumen con 9935 ciudadanos (7220 ingleses) en el país (Dirección General de Estadísticas 1931-1933, vol. II: X), los capitales de esa nacionalidad también aumentaron entre 1880 (7.500.000 de libras esterlinas) y 1890 (24.000.000), hasta llegar hacia 1913 a 55.922.729 de libras esterlinas. En esta última cifra eran importantes las inversiones establecidas en los ferrocarriles (23.065.422 de libras esterlinas) y en la industria salitrera (10.052.214), considerando las dos provincias productoras la de Tarapacá y Antofagasta (Soto 1998: 36; Couyoumdjian 1986: 38). También se puede estimar que la provincia de Antofagasta en 1907 había superado a la de Tarapacá en el número de británicos residentes (2064 frente a 1407). Valparaíso seguía concentrando una diferencia a su favor, con 2.187 británicos y, por consiguiente, iba modificándose la relevancia de la industria salitrera desde Iquique hacia Antofagasta y con ella la incidencia de las casas comerciales, agencias y empresas salitreras. Ésta se percibía hacia 1911, de acuerdo con Hernández (1930: 160-161), al comparar las respectivas descargas, movilización y derechos de exportación. 
Si se observa la presencia de británicos en la recién creada provincia de Antofagasta en 1888, se puede constatar una dispersión más o menos pareja en los tres departamentos como lo revela el censo de 1895: en Antofagasta había 314 súbditos, con 289 hombres y 25 mujeres; en Tocopilla un total de 188 , divididos en 179 hombres y 9 mujeres y en Taltal, 210 con 188 hombres y 12 mujeres (Oficina Central de Estadísticas 1900, vol. I: 129-131).

Las grandes casas comerciales británicas eran a su vez propietarias de algunas oficinas salitreras, operadoras de los muelles de exportación del nitrato, importadoras de enseres e implementos para la industria $y / o$ representantes de determinadas empresas o compañías salitreras. Para algunos autores, las casas comerciales posibilitaron acelerar el proceso de industrialización del país y algunas de ellas, como la Casa Gibbs impresionó como habilitadora de empresas extranjeras y nacionales para la exportación de salitre y otros recursos (Salazar 2007: 682). Desde 1897 funcionó en Antofagasta una sucursal del Banco Anglo Sudamericano que apoyó las inversiones en la industria salitrera y la municipalidad de Antofagasta pudo negociar un empréstito británico en 1914 (Couyoumdjian 2010: 84, 88).

En 1926 la firma Buchanan, Jones y Cía., era la agente de la Compañía Salitrera El Loa y agente de compañías de seguro y de accidentes del trabajo; Barnett y Cía, era propietaria de la mina de cobre "Lomas Bayas" (próxima a la estación ferroviaria de Baquedano), importaba carbón inglés para las oficinas salitreras y era propietaria de un muelle, flota de lanchas y remolcadores en Antofagasta; Duncan, Fox y Cía., era importadora y exportadora de mercaderías en general, importadora de sacos salitreros y agente general en América del Sur de Union Oil Company of California; la poderosa Casa Gibbs y Cía, representaba a la compañía de salitre The Alianza Company Ltd. y los negocios de importaciones y exportaciones cubrían una gran gama, lo que la obligó a disponer de secciones especiales: mercaderías, vapores, seguros y automóviles. Otros establecimientos surgidos en Londres, fueron Nitrate Agencies Ltd., cuyo rubro era el comercio de importación y exportación de mercaderías, la administración de su muelle, lanchas y remolcadores, además de ser compañía de seguro; Williamson y Cía., también trabajaba el ámbito de las importaciones y exportaciones de mercaderías en general y de maquinarias; Lewis y Cía., era una barraca de madera que también extendía sus actividades hacia lo marítimo (Valenzuela 1926: 115-121). El orgullo británico descansaba en el emprendimiento de los hermanos Santiago y Luis Orchard que erigieron la Fundición Orchard en Antofagasta, dedicada a las reparaciones de maquinarias salitreras y que contaba con un horno de fundición de acero "Bessemer", único instalado en América del Sur. En 1905, con la renovación de sus instalaciones, pudieron "servir a la industria salitrera y minera en todas sus necesidades" (Pinto y Ortega 1991: 89).

Hubo firmas británicas que tuvieron una injerencia directa en las oficinas salitreras en lo que respecta a sus representaciones, siendo la más influyente la casa Gibbs $\&$ Co. La firma Harrington, Morrison $\&$ Co., tuvo a su cargo la Oficina Carmela; Williamson, Balfour y Cía, las oficinas Aurelia y Celia y la importante Inglis Lomax y Cía. representaba a la Compañía Salitrera Pampa Alta, con las oficinas Esmeralda, Candelaria, El Loa y Luisis (Silva 1910).

Por su parte, la población británica vinculada directamente con las actividades productivas de la industria salitrera, nos conduce a las labores realizadas por la Compañía de Salitres y Ferrocarril de Antofagasta, surgida de la reorganización de la firma Milbourne Clark \& Co., en 1872 (Mayo 1979: 77). La expansión de la oficina salitrera Antofagasta desde Carmen Alto, a $11 \mathrm{~km}$ de la costa, hacia las explotaciones de Pampa Central y Pampa Alta, entre 1890-1900 (Semper y Michels 1908: 79-83), exigió más personal calificado.

Desde el decenio de 1880, el directorio de la Compañía de Salitres y Ferrocarril de Antofagasta vio la necesidad de contar con personal especializado para abordar la expansión de sus actividades. Incluso después de convenirse la enajenación del ferrocarril, acordada por el directorio de la Compañía, en la sesión de 3 de febrero de 1887 (FSA vol. 4, Acta 526). Blakemore escribió que la fecha 28 de noviembre de 1888 debía considerarse como el día de nacimiento de la empresa Ferrocarril de Antofagasta a Bolivia, aunque la aprobación de la venta por parte del gobierno chileno y de Bolivia se verificó el 2 de abril y el 8 de diciembre de 1889 (Blakemore 1996: 46-47).

Es posible precisar que desde 1880 el reclutamiento de profesionales fue un tema recurrente para el directorio de la Compañía de Salitres: procurar en Inglaterra el personal médico que pudiese abarcar las necesidades de los operarios de las oficinas salitreras y cubrir el servicio en la 
ciudad de Antofagasta. El avance hacia el desierto exigió la presencia de un médico, por ejemplo, en Salinas (FSA vol. 2, Acta 170). Al directorio de la empresa le preocupaba que los orígenes de determinadas enfermedades fuesen todavía desconocidos y afectaran a mecánicos ingleses (FSA vol. 2, Acta 135). Para evitar la fuga de los galenos, como Le Fort que renunció en diciembre de 1882 como médico de la ciudad "i en las calicheras", el directorio acordó doblar el sueldo al Dr. Eduardo Neill, en compensación por la pérdida de clientela en el puerto, pues debía consignar en el contrato "que fije su residencia en Pampa Central, como médico de la calichera" (FSA vol. 3, Acta 226). El Dr. Neill fue uno de los fundadores de la Junta de Beneficencia de Antofagasta en 1875, que estaba a cargo del hospital (Arce 2004: 187). Empero, el clima, las distancias y las incomodidades para la vida personal y familiar - para la que se solicitaba casa, alimentos, subvenciones, etc.-, no lograron estabilizar el servicio médico. Neill, en enero de 1883, renunció y el directorio de la Compañía de Salitres fijó una política para contar con un médico en la ciudad, nombrándose al Dr. Latus en 1883, y otro para Pampa Central, el Dr. Rencoret, quien se retiró en marzo de 1884, asumiendo Latus el servicio calichero junto con un practicante (FSA vol. 3, actas 317, 318, 380). Sería largo centrarnos en esta problemática donde las circunstancias obligaron a contratar médicos chilenos pero en lo concerniente a los súbditos británicos se contó de modo preferente con personal contratado en Londres. La empresa de ferrocarril erigió un hospital en Antofagasta, abierto a toda la colonia británica para cubrir accidentes, patologías e incluso operaciones menores con médicos y enfermeras inglesas hasta bien entrado el siglo XX, e incluso no cerró el suyo (levantado en 1906) cuando se inauguró el Hospital del Salvador en Antofagasta, en 1913 (Blakemore 1996: 121-125). También hubo una política proclive hacia la contratación de mecánicos e ingenieros que pudiesen hacerse cargo de las maquinarias e instalaciones en la pampa, o de las locomotoras y vagones del ferrocarril en la ciudad. No se desatendió tampoco lo referente a los procesos de beneficios y adelantos tecnológicos para la industria del nitrato, por lo que se tuvo contratos con diversos ingenieros, franceses y alemanes, para poder mejorar la producción y disminuir los costos energéticos hasta que, finalmente, irrumpió la tecnología traída por James Humberstone.

Importa mencionar los esfuerzos llevados por la empresa en esta íntima relación de costo/beneficio que significó la provisión de agua y energía y el mejoramiento de los procedimientos tecnológicos. En julio de 1883 urgía la necesidad de "colocar una bomba con motor de viento para poder continuar los trabajos del pozo" desde donde se extraía el recurso hídrico, que daba 100 arrobas de agua (FSA vol. 3, Acta 348). ${ }^{4}$ La necesidad del suministro de agua condujo a determinadas innovaciones: agua de destilación solar suficiente para el consumo y venta que hacía la empresa. Para julio de 1884, lo que se extraía en Salar del Carmen se dejó de realizar y se concentró la producción de agua en Carmen Alto y en Antofagasta (FSA vol. 3, Acta 395). En Carmen se instaló una máquina de agua que finalmente se enajenó en agosto de 1885 (FSA vol. 3, actas 449, 452).

La demanda por ingenieros que pudiesen mejorar los procesos de tratamiento del caliche y los estudios de la ampliación de la red ferroviaria para cubrir la producción nitrosa y la argentífera de Caracoles, constituyó una preocupación temprana. Josiah Harding se encargó de los ferrocarriles: en enero de 1883 solicitó un "carro especial tirado por mulas para estudiar el desierto y la prolongación del ferrocarril" (FSA vol. 3, Acta 317).5 Al despuntar la década de 1880 el directorio de la Compañía de Salitres endosó al administrador de las oficinas salitreras, la responsabilidad de contratar ingenieros o renovar el contrato a los que ya estaban vinculados, como fueron los casos de Mr. Adamson o Mr. Barker (FSA vol. 2, Acta 182). Finalmente, la Compañía ideó un sistema de contratación directa en lo que respecta a los ingenieros, como Mr. Spencer, en 1882, o Mr. Clemenson, que retornó a Inglaterra en mayo de 1883, después de trabajar cinco años como jefe de maestranza del ferrocarril (FSA 3 , actas 334,335 ). Las frecuentes renuncias del personal más calificado, como el ingeniero Mr. Barker, en mayo de 1883 (FSA vol. 3, Acta 337), obligaron a la empresa a fijar una política tríplice: primero, la contratación de un ingeniero con residencia en Londres para todo lo concerniente a la calidad de los materiales encargados a firmas especializadas para los procesos de lixiviación de cali-

\footnotetext{
4 El valor del agua se incrementaba en Pampa Alta y en Carmen Alto donde funcionaban las oficinas salitreras: once ctvos la arroba valía lo que producía la Compañía y se pudo paliar por la oferta del Sr. Peró, de suministrar agua por 40.000 arrobas (cf. FSA vol. 3, Acta 367, 30 de diciembre de 1883).

5 Sobre Harding, cf. Arellano y Roca-Rosell (2013); Twohill (2010).
} 
che. ${ }^{6}$ Segundo, la tarea de reclutar personal técnico europeo, de preferencia en Inglaterra, bajo una modalidad de enganche más sofisticado que el empleado en Chile. Respecto a los mecánicos contratados en Inglaterra en 1881, sus contratos fueron renovados de acuerdo a su rendimiento, y parte de sus remuneraciones fueron retenidas por la Compañía de Salitres para efectos de ahorros o para depositarlos en Londres fijando el cambio de moneda (FSA vol. 3: actas 22, 374, 376). También se procuró personal inglés para los puestos de tenedor de libros o de cajero (FSA vol. 3: Acta 383). De igual modo se buscó en Europa, en septiembre de 1889, "un artesano competente i práctico en la fabricación de pólvora para minas" (FSA vol. 4: Acta 648). Uno de los oficios más difíciles de proveer en el mercado laboral regional fue el de electricista. La instalación eléctrica de la Compañía, que provino de la empresa Siemens \& Halske, en diciembre de 1894, hizo más difícil encontrar a la persona competente. A falta de electricista en Antofagasta, se encargó a ingenieros y mecánicos "tratar de ponerse al corriente del fenómeno de la instalación eléctrica y su manejo" (FSA vol. 6: actas 933, 907). Para fines de siglo todavía constituía un problema la carencia de electricistas, máxime cuando los repuestos eléctricos se encargaban a Europa fiscalizados por el ingeniero Prosh (FSA vol. 6, acta 1045). Es posible conjeturar que desde 1919 se pudo contar con ingenieros electricistas no sólo para las necesidades ferroviarias sino para la industria calichera, fuesen ingleses como Charles Mundy Devison (AHE caja 135 (P) 1394); Henry Clements Leale (AHE caja 130 (P) 45034; quien se fue a Chuquicamata en 1924); Harry Kromas Seifert (AHE caja 133 (P) 67079), o escoceses como George Logan Fainley (AHE caja 134 (P) 95697) quien se vinculó a la Oficina María Elena en 1930. Un último eje de esta política fue buscar firmas de ingenieros para estudiar sistemas que pudiesen ser factibles y abaratar los costos en el tratamiento de los minerales en que estaba trabajando la empresa (FSA vol. 3, actas 346, 354, 373). Una expresión de esta inquietud, fue el acuerdo del directorio en abril de 1883 , concerniente a:

6 Esto después de resultar con fallas unos evaporadores ingleses destinados a Salar del Carmen, lo que provocó gran preocupación en el directorio de la Compañía. En Noviembre de 1883, el directorio designó a cargo de esta materia al ingeniero Mr. Woods (FSA vol. 3, Actas 350, 13 de agosto de 1883; 355, 26 de septiembre de 1883; 361, 5 de noviembre de 1883).

7 En ésta y en las siguientes referencias a este archivo (AHE), la abreviación "(P)", refiere a "prontuario". "...la necesidad que tiene la dirección de este negocio en su parte científica de tener en la Administración General un ingeniero consultor que estudie la solución de los diversos problemas que están pendientes en el beneficio del salitre, yodo, ácido bórico $i$ regeneración de la sal" (FSA vol. 3, acta 334).

Para ello se mantuvo un nexo entre los técnicos que operaban en la pampa (FSA vol. 3, acta 342), que por años recayó en el ingeniero Enrique Jequier, domiciliado en París. En la sesión de 19 de enero de 1885, se tomó nota de que:

“[... se ha implementado en Tarapacá un nuevo sistema de elaborar salitre, sistema introducido en la Oficina Agua Santa y que hoy es conocido como nuevo sistema de elaborar salitre en $\mathrm{Ta}$ rapacá y con el cual se ahorra en aquella provincia la mitad del carbón que antes se usaba" (FSA vol. 6, acta 421).

Se intentó perfeccionar los modelos usados en Antofagasta, como los ideados por Weissflog (FSA vol. 3, actas $334,344,378$ ) o Elphick (FSA vol. 3, acta 338). Este último fue comisionado por la Compañía de Salitres para viajar a Tarapacá y para estudiar detenidamente si este nuevo sistema (el Shanks) era aplicable a sus oficinas (FSA vol. 6, acta 421).

Comenzaba un nuevo ciclo en la explotación y elaboración del salitre en Antofagasta. La introducción del nuevo sistema de elaboración por Santiago Humberstone -un invento de James Shanks y también de Le Blanc (Wisniak y Garcés 2001) - cerró la búsqueda por una mayor optimización de los modelos de elaboración hasta bien entrado el siglo XX. Empero la Compañía siguió buscando otras alternativas en torno al sistema de evaporación que se empleaba, como la sugerencia de los ingenieros Francisco Puelma y Máximo del Campo "de elaboración por solo disolución" (FSA vol. 4, acta 556). Hacia fines del siglo XIX la Compañía no cejaba de experimentar otros ensayos sobre el tópico, como la "cristalización del salitre en bateas con crucetas de madera y sin ellas" (FSA vol. 6, acta 1027).

Pero no fue solamente a través de la Compañía de Salitres y Ferrocarriles de Antofagasta que los británicos intervinieron en la minería regional. Muchos súbditos de la Reina Victoria se vincularon con los negocios mineros y para ello espigaremos en los protocolos notariales de 


\begin{tabular}{|c|c|c|c|c|c|c|c|c|}
\hline $\begin{array}{c}\text { Departa- } \\
\text { mento }\end{array}$ & $\begin{array}{c}\text { Población } \\
\text { Urbana Hom- } \\
\text { bres }\end{array}$ & $\begin{array}{c}\text { Población } \\
\text { Urbana } \\
\text { Mujeres }\end{array}$ & $\begin{array}{c}\text { Población } \\
\text { Urbana } \\
\text { Total }\end{array}$ & $\begin{array}{c}\text { Población } \\
\text { Rural } \\
\text { Hombres }\end{array}$ & $\begin{array}{c}\text { Población } \\
\text { Rural } \\
\text { Mujeres }\end{array}$ & $\begin{array}{c}\text { Población } \\
\text { Rural } \\
\text { Total }\end{array}$ & $\begin{array}{c}\text { Población } \\
\text { Hombres } \\
\text { Total }\end{array}$ & $\begin{array}{c}\text { Población } \\
\text { Mujeres } \\
\text { Total }\end{array}$ \\
\hline Antofagasta & 1174 & 52 & 1126 & 187 & 9 & 196 & 1361 & 61 \\
\hline Tocopilla & 220 & 29 & 249 & 31 & 4 & 35 & 251 & 33 \\
\hline Taltal & 246 & 26 & 272 & 71 & 2 & 73 & 317 & 28 \\
\hline Total & 1640 & 107 & 1647 & 289 & 15 & 304 & 1929 & 122 \\
\hline
\end{tabular}

Tabla 1. Población británica en 1907 (Comisión Central del Censo de 1908: 78, 88, 99).

las iniciativas llevadas a cabo de modo individual en la década de 1890.

Desde Antofagasta, determinados ingleses residentes otorgaron poder especial a parientes y amigos para adquirir acciones en minas en Bolivia, como Juan Segundo Faull (NACM vol. 52, 1892, inscripción 44); ${ }^{8}$ William Murray (NACM vol. 54, 1892, insc. 402); Juan Hulman (NAPA vol. 64, 1894, insc. 552); Guillermo Penny Craig (NAPA vol. 58,1893 , insc. 24) etc., pero lo más significativo y desconocido a la vez fue la injerencia en la pequeña propiedad minera principalmente en el mineral de plata de Caracoles como en otras minas de cobre en el desierto de Atacama. Alfredo Bowden, por ejemplo, fue propietario de la mina de cobre Providencia, de la que finalmente se deshizo, incluyendo sus "22 bienes muebles", en octubre de 1892 (NACM vol. 53, 1892, insc. 1056). Roberto Landerdale Maitland explotó las sulfateras Fortuna Primera y Fortuna Segunda, las que enajenó posteriormente en mayo de 1892 (NAPA vol. 65, 1893, insc. 1181). La firma Walker y Cía fue la intermediaria en la venta de barras de la mina Buena Esperanza de oro y plata que se localizaba en el mineral de Sierra Gorda. La firma tenía como socio a Norman Walker (NAPA vol. 59, 1893, insc. 1654). Cerca de ese poblado el escocés Guillermo Coghill adquirió barras de una mina en el mineral de Punta Negra, en septiembre de 1893 (NAPA vol. 59, 1893, insc. 1129). El inglés Thomas Vance era dueño de un establecimiento minero ubicado en las orillas del río Loa que, en agosto de 1893, arrendó al francés Carlos Mason. Fueron estas compraventas menores de barras de metales las que caracterizaron la presencia británica en la pequeña minería, como aconteció con Norman Walker y la mina Salvador ubicada en el mineral San Cristóbal (NAPA vol. 75,1895 , insc. 1810), o el arrendamiento de la mina Cuspina ubicada en el mineral de Caracoles por parte de

\footnotetext{
8 En adelante se utilizará abreviación "insc."
}

José M. Walker (NAPA vol. 75, 1895, insc. 1532), o la cesión por parte de Guillermo Whittle de una barra aurífera proveniente del mineral San Cristóbal (NAPA vol. 75, 1895, insc. 1217). La misma modalidad empleó Eduardo Hopkins con sus derechos en los mantos de cobre "Calichero", "Salitrero" y "Río Tinto" en la subdelegación de Cobija (NAPA vol. 75, 1895, insc. 540). Carlos Baur, a través de la Sociedad Fundición Templeman, otorgó un poder especial para comprar metales y otras operaciones a nombre de la fundición en el mineral de Caracoles (NAER vol. 75, 1895, insc. 1819). Establecida en Chile desde 1902, la Borax Consolidated Ltd., organizada en Londres con un capital de 469.000 libras esterlinas, se dedicó a la explotación de las borateras de Ascotán (Valenzuela 1926: 190).

En cuanto a inversiones como a presencia demográfica en la minería regional, la acción británica participó también en otras empresas ferroviarias y en la constitución de compañías salitreras en la zona. Habrá que consignar que el ferrocarril todavía vinculado a la Compañía de Salitres debió encarar la competencia de las carretas de empresas establecidas en Antofagasta, como la de Abraham Vallejo en el transporte de la producción del mineral de Caracoles hacia la ciudad de Antofagasta, o la derivada de la oferta de agua de la planta de evaporación solar de Salinas en la década de 1870. Hubo una aspiración a establecer el monopolio del recurso hídrico, cuando la empresa del FCAB compró los derechos de las concesiones otorgadas a la Compañía de Huanchaca (González 2012).

\section{* InVersiones y capital social británicos EN LA PAMPA CALICHERA}

Los británicos en Antofagasta intentaron replicar lo que hizo Thomas North en Tarapacá, es decir la formación de un enclave productivo con sus correspondientes "es- 
tacas" salitreras, con el ferrocarril, el control del agua y el embarque y desembarque de sacos de nitrato así como de mercaderías y maquinarias.

Hemos indicado que el centro de las operaciones británicas fue la ciudad de Antofagasta, empero cuando comienza la expansión británica hacia el control de las oficinas salitreras, la distribución del personal británico hacia la pampa salitrera quedó registrada como población rural (Tabla 1).

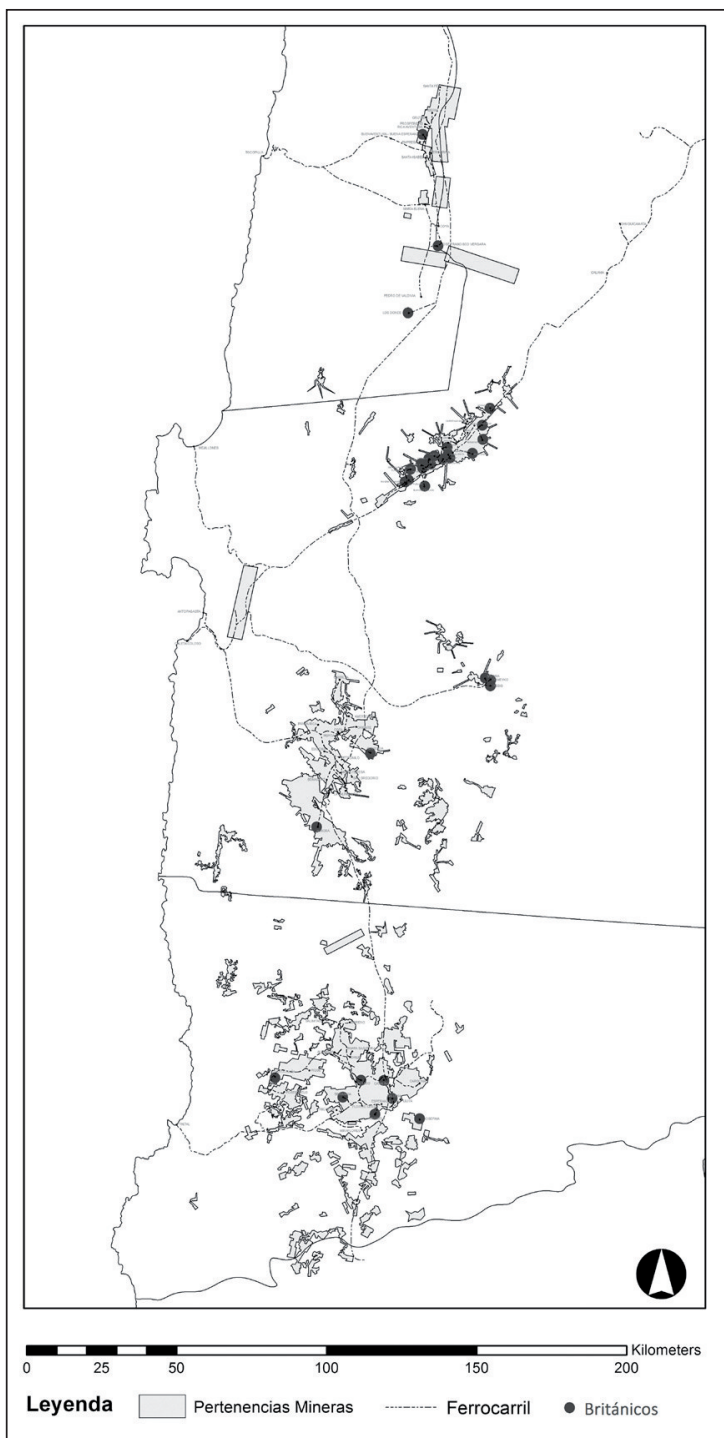

Figura 1. Oficinas salitreras británicas en Antofagasta (1910 - 1926). Elaboración propia en base a la información de Silva (1910, 1914, 1919) y Valenzuela (1926).
Los ferrocarriles fueron relevantes en las inversiones británicas. Bajo la dirección -y propiedad- de Jorge Stevenson, The Taltal Railway Company Ltd., se transformó en 1881 en la empresa británica que cubrió el área sur de las oficinas salitreras de la región de Antofagasta (Thomson 2003: 65). En Tocopilla, el ferrocarril que operaba con las oficinas salitreras era de propiedad de The Anglo-Chilean Nitrate \& Railway $C^{\circ}$ Ltd., y estaba avaluado en $\$ 2.373,454$ (Espinoza 1897: 99). Todas las empresas ferroviarias que comunicaron a los puertos de Taltal, Tocopilla, Coloso, con los cantones salitreros terminaron siendo administrados por The Antofagasta and Bolivia Railway Company Ltd. (FCAB). Esta empresa tubo una interrelación muy fuerte con la industria del salitre, pues en 1918 transportó el $38 \%$ de la producción nacional de nitrato de sodio y el tráfico mencionado significó el $86 \%$ de todo el tráfico de carga descendiente del FCAB (Thomson 2006: 143). Su importancia se reflejó en la fuerte inversión británica para levantar la maestranza de Mejillones en 1906, que revitalizó al puerto de Mejillones (Panadés y Ovalle 1991).

Los británicos, a través de la empresa de ferrocarriles de Antofagasta a Bolivia, controlaron todo el embarque y desembarque de la producción salitrera regional como del abastecimiento de mercaderías y maquinarias hacia las distintas oficinas salitreras. Esto se puede comprender con la configuración de las líneas ferroviarias de Taltal, Tocopilla, Coloso y Antofagasta hacia el interior de la región y los diversos ramales para alcanzar las oficinas salitreras, a veces con dirección hacia una estación del ferrocarril o bien directamente como la línea que se extiende desde Antofagasta hacia Oruro conectando las oficinas salitreras ubicadas hacia el oriente y poniente del tendido ferroviario. En la Tabla 2 podemos observar este nexo.

Los capitales británicos también alcanzaron sectores cruciales de la producción minera, como fue el establecimiento beneficiador de metales Bellavista, de Carne y Knuckey, y de Guillermo Williams. Para 1896 se encontraban posesiones salitreras de Fisher y Co., en Aguas Blancas, por valor de $\$ 40.000$, mientras Baur y Guillermo Mathews tenían establecimientos en la comuna de Calama, que sumaban entre ambos $\$ 62.000$ (Espinoza 1897: 108).

Además de las gestiones que hemos observado en Antofagasta, los británicos se interesaron en la expansión de sus inversiones en las restantes oficinas salitreras. Lo 


\begin{tabular}{|c|c|}
\hline Oficina salitrera & Estación del FCAB \\
\hline Francisco Puelma & Carmen Alto \\
\hline Sargento Aldea & El Buitre \\
\hline Carlos Condell & Carmen Alto \\
\hline Chacabuco & Salinas, a $1.150 \mathrm{~m}$ de distancia \\
\hline Aurelia & Salinas, a 4 km de distancia \\
\hline Blanco Encalada & Salinas, a $7 \mathrm{~km}$ de distancia \\
\hline Ausonia & Peineta, a $3,5 \mathrm{~km}$ de distancia \\
\hline José Santos Ossa & José Santos Ossa \\
\hline Agustín Edwards & Central \\
\hline Aníbal Pinto & Maipú, a 1 km de distancia \\
\hline Arturo Prat & Maipú, a 1,2 km de distancia \\
\hline Cecilia & Peineta, a 9 km de distancia \\
\hline Luisis & Unión, a $4 \mathrm{~km}$ de distancia \\
\hline Anita & Unión, a 1 km de distancia \\
\hline Araucana & Unión, a $5 \mathrm{~km}$ de distancia \\
\hline Rosario & Barazarte, a $38 \mathrm{~km}$ de distancia \\
\hline Bonasort & FCAB, ramal a Aguas Blancas \\
\hline Eugenia & Yungay, a $19 \mathrm{~km}$ de distancia \\
\hline Yugoslavia & Yungay \\
\hline Castilla & Yungay, a $33 \mathrm{~km}$ de distancia \\
\hline Avanzada & Yungay \\
\hline Dominador & - \\
\hline Savona & Savona, a $2 \mathrm{~km}$ de distancia \\
\hline Carrera, ex Domeyko & - \\
\hline Cochrane, ex Pissis & - \\
\hline
\end{tabular}

Tabla 2. Oficinas salitreras y estaciones ferroviarias (Valenzuela 1926; Croquis General de Ferrocarriles y Oficinas Salitreras, Escala 1/500.000. Antofagasta, 1929).

llevado a cabo por Daniel Oliva en el departamento de Taltal con sus cinco oficinas salitreras, derivó en la adquisición de una parte de ellas por la empresa británica The Lautaro Nitrate Company (Hernández 1930: 86).

Los capitales británicos irrumpieron en la propiedad salitrera con fuerza entre 1910 y 1926, como puede visualizarse en la Figura 1, con dominios en los cuatro cantones salitreros: el Central o Bolivia, el de Aguas Blancas, el de Taltal y El Toco. Hacia 1910, las empresas salitreras británicas poseían las siguientes oficinas:

The Lautaro Nitrate Co.: Oficinas Santa Luisa, Ballena, Lautaro y Santa Catalina. The Amelia Nitrate Co. Ltd.: Oficinas Cecilia, Amelia y Aurora. Ghysela Nitrate Co.: Oficina Ghysela. Pacific Nitrate Co.: Oficinas Celia y Aurelia, que llevaban cuatro años de funcionamiento (Silva 1910; Semper y Michels 1908: 340-341). Para el año 1911, se agregaron The Tarapacá and Tocopilla Nitrate Co., con la oficina Santa Fe. A su vez, The Fortuna Nitrate Co., explotaba la oficina Carmela y The Lilita Nitrate Co. Ltd., la oficina
Lilita. A mediados de la década, la empresa The Britannia Nitrate Co. Ltd., explotaba la oficina Britannia, en el cantón de Taltal; The Esperanza Nitrate Co. Ltd., lo hacía con la oficina Esperanza, en el mismo territorio cantonal. The Florencia Nitrate Co. Ltd., comenzaba a operar la oficina Florencia, en el cantón Central, al igual que The Leonor Nitrate Company Ltd., con la oficina Leonor (Silva 1914).

Hacia fines del decenio, en 1919, The Fortuna Nitrate Co. tomó el control de las oficinas Aurelia y Celia, además de proseguir con el dominio de la Oficina Carmela; The Aguas Blancas Nitrate Co. administraba la oficina Eugenia, y The Tarapacá \& Tocopilla Nitrate Co., seguía funcionando con la oficina Santa Fé. The Lautaro Nitrate Co. continuaba con el funcionamiento de sus oficinas establecidas en el cantón de Taltal (Silva 1919).

El incremento de personal británico en oficinas salitreras acaeció en julio de 1926 (Arce 2004: 482), cuando la Compañía de Salitres de Antofagasta enajenó sus vastas propiedades salitreras a The Lautaro Nitrate Co. como 
fueron sus oficinas salitreras Francisco Puelma, Sargento Aldea, Carlos Condell, Aurelia, Blanco Encalada, Carmela, Ausonia, José Santos Ossa, Agustín Edwards, Aníbal Pinto, Arturo Prat, Araucana (Valenzuela 1926).

La relación entre la propiedad británica de una oficina salitrera y el personal administrativo de esa nacionalidad fue estrecha, a excepción de cuando una empresa nacional procuraba personal técnico o profesional europeo. Ejemplos de tales nexos se manifestaron extensamente en la pampa calichera, en distintos grados y sin importar el tamaño de la empresa. The Fortuna Nitrate Co., en su Oficina Aurelia, del cantón Central o Bolivia, integró en su cuerpo administrativo a los siguientes súbditos británicos:

Administrador, Thomas C. Peddar; pasatiempo William White; bodeguero Alfredo Trengove; ingeniero Franklin Hampton; jefe de maestranza, George Roy. The Lautaro Nitrate Co. Ltd., en su oficina Ballena del cantón de Taltal, hizo figurar al siguiente personal británico: administrador, P. M. Campbell; contador C. Seelig; cajero y ayudante de contador, W. A. Winton; ingeniero y jefe de maestranza, Federico Richards; jefe del servicio de agua de Piques, C. C. Grant. La oficina Carmela de propiedad de The Fortuna Nitrate Co., tuvo como administrador a Daniel Jones; como contador y cajero a Charles Fairbrass; como bodeguero a Edmundo James. La misma empresa en su oficina Celia, contó con el administrador Thomas W. Orr; el contador E. E. Williams; el ingeniero Frank Hampton.

The Tarapacá \& Tocopilla Nitrate Co. Ltd., en su oficina Santa $\mathrm{Fe}$, registró como administrador a S. H. Elliot; como contador y cajero a E. M. Fitch; como jefe de la casa de yodo, a William Bunch. The Anglo-Chilian Nitrate \& Railway Co. Ltd., mantuvo en sus oficinas Santa Isabel y Peregrina como administrador a J. G. Mc-Culloch; como contador a J. A. Rhind y como químico a W. Mc Dowall.

The Lautaro Nitrate Co., Ltd. en su oficina Santa Luisa tuvo la mayor cantidad de personal británico en una usina del cantón de Taltal: gerente, W. E. Bradley; administrador, W. S. Seaward; ayudante de administrador, A. F. Pollock; contador, A. J. Davis; cajero, V. Messing; empleado, E. Esbry; ingenieros, Pedro Smart y B. R. Phelps; jefe de maestranza, F. T. Young; mecánico, P. Morton; bodeguero de maestranza, R. Smart; jefe de la casa de fuerza, G.
H. Parsons; ayudante, D. Price; químico, W. G. Buchanan (Silva 1919: 291, 293-295, 303, 305, 346-347).

\section{* Análisis del capital social y de redes SOCIALES DE LOS BRITÁNICOS EN LOS NEGOCIOS CONCOMITANTES A LA MINERÍA}

Si examinamos los prontuarios de los británicos provenientes del Archivo Histórico de Extranjería (AHE), del Servicio del Registro Civil e Identificaciones, que totalizan 665 fichas en el período de estudio, ${ }^{9}$ llama la atención que todos los prontuarios están relacionados con la actividad minera de modo directo o indirecto: el personal de los ferrocarriles, de las empresas salitreras y mineras en general, los empleados y comerciantes ligados a casas comerciales mayoristas, los dedicados al rubro de la salud y a las profesiones liberales (ingenieros, contadores, ensayadores); los administrativos de las oficinas salitreras e incluso de los muelles. Ya el censo de 1895 señalaba la existencia, por ejemplo para la región de Antofagasta, de 16 comerciantes, 24 empleados privados, nueve ingenieros y 16 mecánicos (Oficina Central de Estadística 1900: 1591). Si examinamos los pormenorizados datos de los 665 prontuarios británicos, encontramos las siguientes relaciones que nos revelan además la trama socio-laboral en la ciudad de Antofagasta.

\section{a. Contactos familiares y su localización global}

Esta dimensión representa una buena aproximación a la red de soporte familiar que tiene el migrante, y se construye a partir de la información relativa a la presencia de parientes y a su localización, elementos que están registrados en los prontuarios individuales examinados. Dada la naturaleza de la información, y siguiendo ideas contenidas en el trabajo de Massey et al. (1993: 431-466) se puede plantear, en primer lugar, que el tamaño de la red familiar de soporte del inmigrante (TR), medida como el número de relaciones mencionadas en cada prontuario, es una información básica que permite conocer la cantidad de contactos que cada persona tiene como potencial apoyo personal.

\footnotetext{
9 Se descartaron 169 que exceden los años de estudio, que arrojarían 834 prontuarios.
} 
En segundo lugar, se debe considerar la extensión geográfica de la red o su localización global, es decir los diferentes países en los que se ubican los contactos personales del migrante y qué tan importante es la concentración de los contactos en cada uno de ellos. Para esto se requiere utilizar cuatro indicadores básicos: 1) número de países mencionados (NP); 2) porcentaje de los contactos en Inglaterra (PIng); 3 ) porcentaje de los contactos en Chile $\left(\mathrm{PCH}_{i}\right)$; y 4$)$ porcentaje de los contactos en terceros países $(\mathrm{PO})$. Si el patrón de localización fuese estrecho (pocos países) y concentrado básicamente en Inglaterra, se trataría de una migración no permanente, probablemente vinculada a trabajos específicos que implican vivir en otro país pero manteniendo una vinculación fuerte con el lugar de origen. En oposición, una fuerte localización en Chile implicaría que el migrante se desplazó con un conjunto de personas relacionadas, perfil compatible con migraciones de grupos familiares de largo aliento asociadas al desarrollo de proyectos vitales completos. Finalmente, si la extensión geográfica es alta y diversificada, se trataría de familias que han abandonado el lugar de origen fraccionándose en diferentes destinos, lo que es en si mismo una estrategia para minimizar riesgos (Palloni et al. 2001). Este patrón podría indicar una migración más bien especulativa, cuyo enraizamiento definitivo depende de la consolidación de un proyecto local que sea relativamente superior al generado en otras latitudes por los parientes relacionados (Massey 1988).

\section{b. Localización residencial}

La forma en que las personas se ubican en el espacio urbano denota una serie de características, no sólo por la morfología propia de la ciudad y/o el lugar del asentamiento, sino fundamentalmente porque esto condiciona las oportunidades de interacción social que las personas tienen (Feld 1981; Blake et al. 1956). A partir de los trabajos de Schelling (1971), se establece que la localización también refleja preferencias por estar rodeados de vecinos similares (homofilia), lo que puede dar lugar a patrones segregados de residencia y, en el contexto de poblaciones inmigrantes, podría configurar enclaves étnicos o guetos (Schiappacasse 2008).

La información de los prontuarios permite establecer con precisión las residencias, lo que facilita utilizar como indicador fundamental la co-localización, es decir el nú- mero de personas que coinciden en una misma ubicación (sea dirección, establecimiento o área de la ciudad). Esta co-localización aproxima a la red de contactos sociales del grupo, y su extensión muestra la concentración/dispersión de la comunidad en su entorno urbano. Patrones muy concentrados indican un bajo potencial de interacción con el exogrupo y privilegio del endogrupo y, por el contrario, una menor concentración se asocia a un patrón de interacciones sociales potencialmente más extenso y abierto al exogrupo (Vaughan 2002).

Resultados de Redes Sociales y localización (indicadores a). Con relación a los indicadores de redes de familiares y su localización global, los resultados del indicador TR sobre tamaños de redes familiares, señalan que un 13\% de la población inmigrante declaró en los prontuarios no tener familia ni en Chile ni en el exterior, calificando en la categoría de personas solas. Un 48\% presentó entre uno y dos familiares relacionados, proporción que llega al 31\% para los casos de tres a cinco familiares relacionados. Al controlar esta información por la localización de estas relaciones (indicador $\mathrm{NP}_{\mathrm{i}}$ ) queda de manifiesto que el $74 \%$ de los casos mantiene localizadas a sus relaciones en un sólo país, en contra del 12\% que mantiene sus relaciones distribuidas entre dos o más países. Esto valores señalan que las redes de contactos familiares eran más bien concentradas desde un punto de vista geográfico.

Con relación al indicador de proporción de la red familiar residiendo en Inglaterra (o índice PIng.), un 37\% de la población registrada en los prontuarios tiene el 100\% de sus relaciones familiares residiendo en Inglaterra, lo que implica que la totalidad de sus recursos sociales disponibles por medio de estas relaciones están localizados en el exterior del país. En contraste, el indicador de la proporción de la red familiar residiendo en Chile (o índice $\mathrm{PCH}_{\mathrm{i}}$ ) indica que sólo el $26 \%$ tiene el total de su red familiar residiendo en Chile. Cuando a este indicador se le incluyen aquellos que tienen al menos el $50 \%$ de su red familiar residiendo en Chile, el indicador suma sólo un $6 \%$ adicional. Este patrón indica que en general los inmigrantes con familiares mantuvieron una suerte de localización bimodal, una proporción (37\%) de los familiares optó por mantenerse en la metrópolis y otro $33 \%$ optó por desplazar una proporción importante de la familia hacia Chile. 


\begin{tabular}{|c|c|c|c|}
\hline Localización & Según año de filiación & TOTAL & \\
\hline & Entre 1910 y 1920 & Entre 1921 y 1930 & $337(52.2 \%)$ \\
\hline Residencias Particulares & $124(57.4 \%)$ & $213(49.5 \%)$ & $309(47.8 \%)$ \\
\hline Residencias Institucionales & $92(42.6 \%)$ & $217(50.5 \%)$ & $646(100 \%)$ \\
\hline Total & $216(100 \%)$ & $430(100 \%)$ & \\
\hline
\end{tabular}

Tabla 3. Lugar de residencia. Elaboración propia en base a los 665 prontuarios británicos del Archivo Histórico de Extranjería (AHE), del Servicio de Registro Civil e Identificaciones.

Para ilustrar estas circunstancias asociadas a la extensión y localización de la red de contactos familiares, se toman los siguientes ejemplos:

1. Francisco Boyle Ryan, soltero, 23 años, natural de Surrey, ingresa a Chile en 1926. Trabajador del Colegio Inglés, declara tener ocho familiares en su red (AHE caja 129 (P) 72809 ).

2.Walter Hughes Penlington, soltero, 33 años, natural de Cheshire, ingresa a Chile en 1919, declara tener ocho familiares en su red (AHE caja 133 (P) 3693).

3. Almond Bernard Rowe Nautherois, soltero, 33 años, natural de Cornwall, ingresa a Chile en 1922, vinculado laboralmente a la Compañía Gibbs, declara tener ocho familiares en su red (AHE caja 136 (P) 21940).

En estos tres casos la red familiar completa continúa instalada en Inglaterra, situación similar con otros 211 hombres y 30 mujeres (96 casados, 137 solteros, 8 viudos) y que son parte del grupo de $37 \%$ de la población previamente descrita con redes totalmente localizadas en Inglaterra.

En oposición, tenemos los casos en que se encuentra el $100 \%$ de la red familiar localizada en Chile, entre ellos destacan los siguientes casos de grupos familiares e individuos:

4. Familia Swaneck-Negton (Nathal, José, Juan, Pedro, Nicolás, Thomas y Ricardo) todos residentes en Antofagasta, con edades entre 19 y 36 años, naturales de los dominios británicos de Transvaal y El Cabo, en Sudáfrica, que ingresan a Chile entre 1920 y 1930 . Ellos identifican una red extensa de más de 12 familiares todos localizados en Chile (AHE caja 137 (P) 63957 , 4708, 7242, 11136, 1218, 8688 y 9819).
5. Familia Pridham-Stevenson (Herbert y Juana), residentes en Antofagasta, con edades de 29 y 18 años, naturales de Londres y Surrey, ingresan a Chile en 1919. Ellos identifican una red limitada compuesta sólo por su hermano(a) (AHE caja 136 (P) 7583 y 5774).

6.Familia Buchanan-Young (Elizabeth, Allison y Andrés), residentes en Antofagasta, con edades de 40 y 36 años, naturales de Slamannan y Glasgow, Escocia. Ingresan a Chile en 1930, 1927 y 1920. Ellos identifican una red limitada compuesta sólo por sus hermanos y un cónyuge (AHE caja 138 (P) 101.169, (P) 77092 y 9257).

7. John Christie Gouk, casado, 28 años, natural de Glasgow, Escocia. Ingresa a Chile en 1925, a trabajar en Chuquicamata, declara tener siete familiares en su red, todos residentes en Chile (AHE caja 130 (P) 53380).

8.Alberto Lyons Johnson, casado, 30 años, natural de Conwell, Inglaterra. Ingresa a Chile en 1920, comparte su residencia entre Antofagasta y Mejillones, declara tener cinco familiares en su red, todos residentes en Chile (AHE caja 134 (P) 9546).

En estos casos la localización en Chile de toda la red familiar es indicativa de una forma de migración distinta, orientada al desarrollo de un proyecto vital completo en el país de destino. Este grupo está compuesto por 171 personas, 127 hombres y 44 mujeres (142 casados, 22 solteros, 7 viudos) y que son parte del grupo de $26 \%$ de la población previamente descrita con redes totalmente localizadas en Chile.

Resultados de Localización Residencial (indicadores b). El análisis de co-localización se llevó a cabo utilizando las residencias declaradas en los prontuarios En ese sentido es posible construir una tabla de doble entrada entre las localizaciones y los años de ingreso al país. Para esto se 
optó por agrupar todas las propiedades identificables del Ferrocarril Antofagasta a Bolivia (FCAB) como una única localización, lo mismo se hizo con los denominados "ranchos" de diferentes compañías, hoteles y pensiones, constituyendo lo que se ha denominado residencias institucionales. Por otra parte, las residencias localizadas en las diferentes calles y numeraciones han sido definidas como residencias particulares. Se espera que, a medida que la ciudad va creciendo y se expande urbanísticamente, las personas que optan por establecerse en la ciudad fijen su residencia fuera de las residencias institucionales (Tabla 3).

La información indica que en general la población inmigrante se distribuyó en este tipo de residencias, particulares e institucionales, de una manera relativamente pareja $(52 \% \mathrm{v} / \mathrm{s} 48 \%)$ en todo el período de análisis. Cuando se controla según los períodos de afiliación, se aprecia una diferencia a favor de las residencias institucionales en el período más tardío, lo que supone un patrón diferente al esperado, puesto que al crecer la ciudad aumenta también la primacía de las residencias institucionales, lo que supone una intensificación del potencial de relaciones endogrupales en desmedro de las relaciones exogrupales.
Cuando esto se evalúa considerando la concentración del patrón de localización, las residencias particulares aparecen mucho más diversificadas y esta diversificación aumenta conforme se pasa del primer período al segundo, lo que implica una expansión de las oportunidades de interacción con otros fuera del grupo de inmigrantes británicos. La concentración de las residencias institucionales es casi tres veces mayor que las particulares, pero esta concentración también se reduce conforme se pasa del primer al segundo período, es decir al crecer la ciudad y a pesar de que un mayor número de inmigrantes británicos reside en localizaciones institucionales bajo en dominio de compañías particulares, el grado de concentración en estos sitios específicos se reduce en comparación al período anterior, lo que apoya la hipótesis de que al crecer la ciudad aumentan las oportunidades de mayores interacciones exogrupales.

Con relación a los actores institucionales dominantes, las propiedades ligadas al FCAB concentran al 17. $8 \%$ de los residentes ingleses del período, siendo el mayor aporte en cuanto a localización residencial del grupo. Otros actores importantes en este sentido son también: el rancho

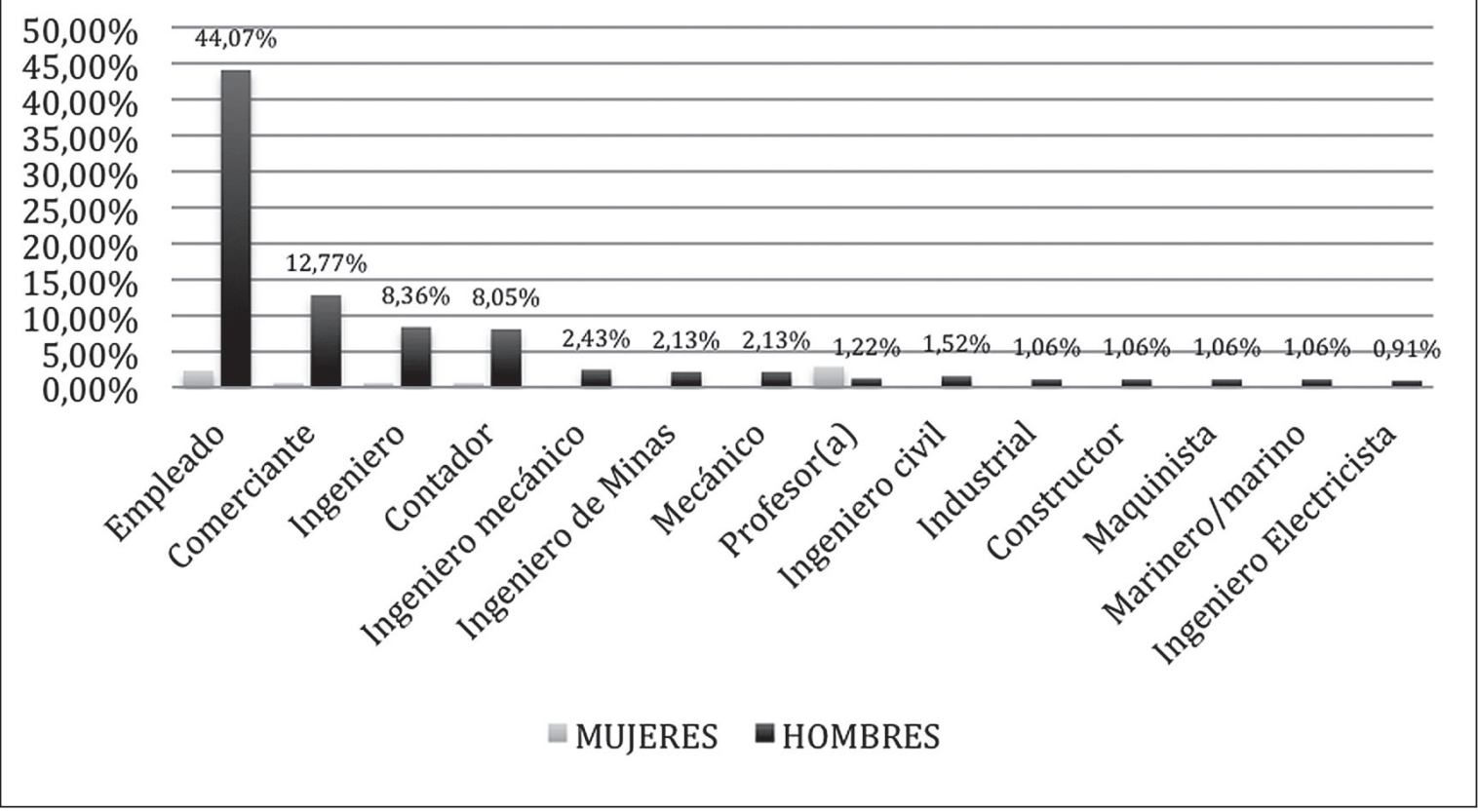

Figura 2. Ocupaciones británicas en la región de Antofagasta. 
Gibbs (5,2\%), el rancho del Banco Anglo (4,8\%), los hoteles Maury $(4,5 \%)$ y Londres (4,3\%). Al comparar las localizaciones en residencias particulares, las calles del centro histórico de la ciudad y su extensión hacia el sur presentan las mayores tasas de participación relativa, particularmente las calles Balmaceda $(5,6 \%$ de los residentes); el sector de la Avenida Brasil (5,3\%); Maipú (4,3\%); Salvador Reyes (4,2\%); Prat (3,4\%); Angamos/ Matta (3,1\%) y Washington (2,6\%).

\section{c. La distribución de ocupaciones de los inmigran- tes británicos}

La rica información de los prontuarios individuales permite examinar la distribución de las ocupaciones declaradas por la población inmigrante. Las estadísticas identifican un inventario total de 66 ocupaciones diferentes, incluyendo desde las labores de dueña de casa o de jornalero hasta las de ingeniero y médico. En la Figura 2 se presenta la distribución, separada por hombre y mujeres, de las 14 ocupaciones más frecuentes en la población bajo estudio.

Debe clarificarse que, en consistencia con las costumbres de la época, la tasa de participación laboral de las mujeres es muy baja, sólo el 21 \% declara una ocupación distinta a las labores del hogar, esta misma categoría ha sido excluida del gráfico y representa $75 \%$ de las mujeres inmigrantes.

Entre las mujeres trabajadoras, destacan las ocupaciones de profesoras ( $2,9 \%$ de los casos), empleadas, enfermeras, taquígrafas e institutrices, cada una con una participación individual equivalente al 2,3\% de la población femenina.

En el caso de las ocupaciones de los hombres, destacan las actividades como trabajadores dependientes, las relacionadas con actividades comerciales, las de ingeniería y minería, y sus servicios asociados. A modo de ejemplo, se destacan los empleados con 290 casos (44.1\% de la población masculina), luego 84 comerciantes (13\%); 53 contadores (8.1\%), 104 ingenieros (16\%) que, a su vez, se subdividen en 55 ingenieros sin especialidad, 16 mecánicos, 14 en minas, diez civiles, seis eléctricos, dos químicos y un geólogo de minas. Este conjunto de actividades representa más del 81\% de los inmigrantes británicos y ponen de manifiesto su enorme influencia y control sobre las actividades productivas claves de la época, no sólo controlando la propiedad de la industria del salitre, sino también en la gestión productiva y comercial de la época a partir de la preeminencia del capital humano.

\section{* Conclusiones}

La colonia británica en la región de Antofagasta estuvo presente desde los inicios del desarrollo de la ciudad de Antofagasta y en el despliegue de los negocios que posibilitaron consolidar la explotación del salitre y fundamentalmente crear una red de conectividad ferroviaria que redujo los costos/beneficios de la salida de la producción minera por los puertos calicheros de los cantones del sur y del norte del desierto de Atacama. No escapó a las casas comerciales con asiento en Londres, controlar la actividad de cabotaje general para las ciudades y del hinterland minero (desde el salitre, plata, cobre hasta el abastecimiento comestible y técnico). En tal sentido, hubo una correlación entre la expansión de los negocios británicos con el acrecentamiento de su colonia, que alcanzó su pick en 1907, cuando la empresa del FCAB logró concretar su maestranza en Mejillones un año antes, demandando una mayor cantidad de personal cualificado.

Los británicos alcanzaron en 1926 el control de la mayoría de las oficinas salitreras. Año que marcó, paradójicamente, el fin de la hegemonía breve de los británicos en la industria salitrera, cuando las inversiones norteamericanas de los Guggenheim, introdujeron su sistema homónimo en el salitre, mientras los británicos laboraban con variantes del sistema Shanks. La crisis de 1930 vino a corroborar la declinación definitiva de los británicos en el salitre y el retroceso de su influencia comercial y demográfica en la región de Antofagasta.

Agradecimientos Este trabajo forma parte del proyecto FONDECYT 1130785, año 2014. 


\section{* Referencias citadas}

\section{Fuentes documentales}

I. Archivo Nacional de la Administración

Fondo Salitrero Antofagasta (FSA)

Actas del Directorio de la Compañía de Salitres.

Vol. 2 (abril 1879-mayo 1881), actas 135, 170, 182, 301;

Vol. 3 (diciembre 1882-agosto 1885), actas 226, 316, 317, 318, $334,337,338,342,344,346,348,350,354,355,373,374,376$, $378,380,383,395,421,449,452$;

Vol. 4 (septiembre 1885-1889), actas 526, 556, 648;

Vol. 6 (diciembre 1894-septiembre 1899), actas 907, 933, 956, 1027,1045 .

Notaría de Antofagasta. Notario Carlos Mancilla (NACM):

Vol. 52, año 1892, Inscrip. 44.

Vol. 54, año 1892, Inscrip. 402.

Vol. 53, año 1892 , Inscrip. 1056.

Notaría de Antofagasta, Notario Pedro Pablo Álvarez (NAPA):

Vol. 58, año 1893 , Inscrip. 24.

Vol. 59, año 1893, Inscrip. 1654.

Vol. 59, año 1893, Inscrip. 1129

Vol. 64, año 1894, Inscrip. 552.

Vol. 65, año 1893, Inscrip. 1181.

Vol. 75, año 1895, Inscrip. 1810.

Vol. 75, año 1895, Inscrip. 1532.

Vol. 75, año 1895, Inscrip. 1217.

Vol. 75, año 1895 , Inscrip. 540.

Notaría de Antofagasta, Notario Enrique Rojas Sotmay (NAER): Vol. 75, 1895, Inscrip. 1819 .

II. Archivo Histórico de la Universidad Católica del Norte

Archivo Histórico de Extranjería (AHE), del Servicio de Registro Civil e Identificaciones: Británicos, cajas 129, 130, 131, 132, $133,134,135,136,137,138,143$.

\section{Publicaciones}

ARCE, I. 2004 [1930]. Narraciones históricas de Antofagasta. Corporación Pro Antofagasta. Antofagasta.

ARELLANO, N. y A. ROCA-ROSELL. 2013. La ingeniería británica de desalación de agua mediante el uso de la energía solar en Chile en el siglo XIX. Quipu, Revista Latinoamericana de Historia de la Ciencia y la Tecnología 15 (2): 163-191.
BERMUDEZ, O. 1963. Historia del salitre desde sus orígenes hasta la Guerra del Pacífico. Ediciones de la Universidad de Chile, Santiago de Chile.

BLAKE, R., C. RHEAD, B. WEDGE y J. MORTO. 1956. Housing Architecture and Social Interaction. Sociometry 19: 133-139.

BLAKEMORE, H. 1977. Gobierno chileno y salitre inglés, 1886-1896: Balmaceda y North. Editorial Andrés Bello, Santiago de Chile. 1996, Historia del Ferrocarril de Antofagasta a Bolivia. 1888-1988. Impresos Universitarios, Santiago.

COMISIÓN CENTRAL DEL CENSO 1908. Memoria presentada al Supremo Gobierno del VIII Censo levantado el 28 de noviembre de 1907. Imprenta Universo, Valparaíso.

COUYOUMDJIAN, J. R. 1986. Chile y Gran Bretaña durante la primera guerra mundial y la postguerra, 1914-1921. Editorial Andrés Bello/ Ediciones Universidad Católica de Chile, Santiago de Chile.

2000. El alto comercio de Valparaíso y las grandes casas extranjeras 1880-1930. Una aproximación. Historia 33: 63-99.

2010. Los británicos en las finanzas. En Legado Británico en Valparaíso-British Legacy in Valparaiso, M. Prain (Ed.), pp. 78-99. Universidad Andrés Bello Viña del Mar/ Instituto Chileno Británico, Viña del Mar/ RIL Editores, British Council, Viña del Mar.

CROQUIS GENERAL DE FERROCARRILES Y OFICINAS SALITRERAS, año 1929. Escala 1/500.000, Antofagasta.

DIRECCIÓN GENERAL DE ESTADÍSTICA, 1931-1933. Resultados del X Censo de la población efectuado el 27 de noviembre de 1930 y estadisticas comparativas con censos anteriores. Imprenta Universo, vols. I-II, Valparaíso.

ESPINOZA, E. 1897. Jeografía descriptiva de la República de Chile. Cuarta Edición. Imprenta i Encuadernación Barcelona, Santiago de Chile.

ESTRADA, B. 2006. La colectividad británica en Valparaíso durante la primera mitad del siglo XX. Historia 39 (1): 65-91.

FELD, S. L. 1981. The Focused Organization of Social Ties. The American Journal of Sociology 86 (5): 1015-1035.

GONZÁLEZ, J. A. 2012. Privatization Versus Public Funding on the Atacama Desert Railway. An Interpretation. En Infrastructure 
Design, Signalling and Security in Railway, X. Perpiña (Ed.), pp. 5168. In Tech, Rijeka, Croacia.

HERNÁNDEZ, R. 1930. El Salitre (Resumen histórico desde su descubrimiento y explotación). Fisher Hnos., Valparaíso.

MARTINIC, M. 2002. La participación de capitales británicos en el desarrollo económico del territorio de Magallanes 18801920. Historia 35: 299-321.

MASSEY, D., J. ARANGO, H. GREAME, A. KOAUOUCI, A. PELLEGRINO y J. EDWARD TAYLOR. 1993. Theories of International Migration: A Review and Appraisal. Population and Development Review 19 (3): 431-466.

MASSEY, D. 1988. Economic Development and International Migration in Comparative Perspective. Population and Development Review 14 (3): 383-413.

MAYO, J. 1979. La Compañía de Salitres de Antofagasta y la guerra del Pacífico. Historia 14: 71-102.

MONTEON, M. 1975. The British in the Atacama Desert. The Cultural Bases of Economic Imperialism. Journal of Economic History 35: 117-133.

O'BRIEN, Th. 1982. The Nitrate Industry and Chile's Crucial transition: 1870-1891. New York University Press, New York.

OFICINA CENTRAL DE ESTADISTICA. 1900. Sétimo Censo Jeneral de la población de Chile levantado el 28 de noviembre de $1895 i$ compilado por la Oficina Central de Estadística. Imprenta Universo (Tomo I), Valparaíso.

PANADÉS, J. y O. OVALLE. 1991. Anexo 1. La Maestranza del ferrocarril Antofagasta a Bolivia en Mejillones. En Expansión minera y desarrollo industrial: un caso de crecimiento asociado (Chile 1850-1914), J. Pinto y L. Ortega (Eds.), pp. 115-136. Universidad de Santiago de Chile, Santiago de Chile.

PINTO, J. y L. ORTEGA. 1991. Expansión minera y desarrollo industrial: un caso de crecimiento asociado (Chile 1850-1914). Universidad de Santiago de Chile, Santiago de Chile.

PALLONI, A., D. MASSEY, M. CEBALLOS, K. ESPINOSA y M. SPITTEL. 2001. Social Capital and International Migration: A Test Using Information on Family Networks. American Journal of Sociology 106 (5):1262-1298.
RAMÍREZ, H. 1972. Balmaceda y la contrarrevolución de 1891. Editorial Universitaria, Santiago de Chile.

RAVEST, M. 1983. La Compañía salitrera y la ocupación de Antofagasta, 1878-1879. Editorial Andrés Bello, Santiago de Chile.

RIPPY, J. F. 1954. British Investment in the Chilean Nitrate Industry. Interamerican Economic Affairs 8 (2): 3-10

SALAZAR, G. 2007. Mercaderes, empresarios y capitalistas (Chile, siglo XIX). Editorial Sudamericana, Santiago de Chile.

SCHELLING, Th. 1971. Dynamic Models of Segregation. Journal of Mathematical Sociology, 1: 143-186.

SCHIAPPACASSE, P. 2008. Segregación residencial y nichos étnicos de los inmigrantes internacionales en el área Metropolitana de Santiago. Revista de Geografía Norte Grande 39: 21-38.

SEMPER, Dr. y Dr. MICHELS. 1908. La industria del salitre en Chile. Monografía publicada en la Revista Oficial de Minas, Metalurjia $i$ Sustancias salinas. Vol. 52, año 1904, Berlin, traducida directamente del alemán $i$ considerablemente aumentada por Javier Gandarillas y Orlando Ghigliotto Salas. Imprenta, Litografía i Encuadernación Barcelona, Santiago de Chile.

SILVA, D. 1910. Guía Administrativa, Industrial y Comercial de las provincias de Tacna, Tarapacá y Antofagasta. Imprenta Gutenberg, Santiago de Chile.

1914. Guía Administrativa, Industrial y Comercial de las provincias de Tacna, Tarapacá y Antofagasta. Imprenta Gutenberg, Santiago de Chile.

1919. Guía Administrativa, Industrial y Comercial de las provincias de Tacna, Tarapacá y Antofagasta. Imprenta Universitaria, Santiago de Chile.

SOTO, A. 1998. Influencia británica en el salitre. Origen, naturaleza y decadencia. Editorial Universidad de Santiago, Santiago de Chile.

THOMSON, I. 2003. Red Norte: la historia de los ferrocarriles del norte chileno. Instituto de Ingenieros de Chile, Santiago de Chile. 2006. Los ferrocarriles del Capricornio Andino. En Las Rutas del Capricornio Andino. Huellas milenarias de Antofagasta, San Pedro de Atacama, Jujuy y Salta, A. Cabezas (Ed. Gral.), pp. 137149. Consejo de Monumentos Nacionales, Santiago de Chile. 
TWOHILL, N. 2010. The British World and its Role in the Relationship between New Zeland and the Southern Cone Countries of South America 1820-1914. Historia 43 (1): 113162 .

VALENZUELA, J. 1926. Álbum Zona Norte de Chile. Informaciones Salitreras (Adquiridas de fuente oficial, al visitar todas las Oficinas de la Pampa. S/d, Santiago de Chile.
VAUGHAN, L. 2002. The Unplanned 'Ghetto': Immigrant work patterns in 19th century Manchester. Paper given at the 1oth Conference of the International Planning History Society, University of Westminster, London.

WISNIAK, J. e I. GARCÉS. 2001. The rise and fall of the salitre (Sodium Nitrate) industry, Indian Journal of Chemical Technology 8: 427-438. 